\title{
Tradisi Tedhak Siten Terkandung Konsep Self Efficacy Masyarakat Jawa
}

\author{
Ana Musdalifah ${ }^{1 *}$, Taufik Akbar Rizky Yunanto ${ }^{1}$ \\ ${ }^{1}$ Program Magister Sains Fakultas Psikologi Universitas Surabaya \\ Jl. Raya Rungkut Kali Rungkut Kota Surabaya 60293 Jawa Timur \\ *Email: ana.musdalifah1982@gmail.com \\ Naskah diterima 21 Januari 2020, Revisi 15 Maret 2021, Terbit 29 April 2021 \\ DOI: doi.org/10.21107/pamator.v14i1.9559
}

\begin{abstract}
The tradition of tedhak siten is still widely believed by Javanese people to this day. In the process of tedhak siten there are 6 stages that must be passed by a child, one of which is a stage in confinement. At parents this stage raises the perception of self-efficacy after the child chooses the items in the cage, it is believed that the items selected are a process of description that will occur in children as adults. The purpose of writing this article is in addition to being interested in the writer wants to understand more scientifically the relationship between culture tedhak siten with psychological aspects, also interested in the relationship between career and family perception. Data was collected through literary source techniques for collecting various related journals and articles. The results of writing this article indicate that the process of tedhak siten ceremony contains values, the goodness that comes from parents for children is able to achieve their ideals, which are closely related to psychological theory, namely self efficacy.
\end{abstract}

Key words: community, values, tedhak siten, self efficacy

\section{PENDAHULUAN}

Tedhak siten menjadi hal yang menarik dimana masyarakat modern yang memiliki ciri khas serba praktis sampai saat ini masih mempercayai dan melaksanakan tradisi tedhak siten di tanah Jawa yang prosesnya cukup rumit, alasannya karena upacara ini dilakukan sebagai ucapan rasa syukur kepada Tuhan di saat seorang anak yang berumur 7-8 bulan mulai menapakkan kaki diatas bumi. Upacara ini biasanya si anak akan diangkat oleh ibu/ ayahnya menaiki beberapa buah anak tangga bambu, kemudian perlahan-lahan turun kembali menapaki anak tangga itu menuju tanah. Upacara pada saat anak turun tanah untuk pertama kali, atau disebut juga mudhun lemah atau unduhan. Masyarakat beranggapan bahwa tanah mempunyai kekuatan gaib, disamping itu juga adanya suatu anggapan kuno bahwa tanah ada yang menjaga yaitu Batharakala. Maka dari itu si anak diperkenalkan kepada Batharakala sang penjaga tanah agar tidak marah dan mengganggu si anak, apabila Batharakala sampai marah berarti bencana akan menimpa si anak.

Perlengkapan yang digunakan pada upacara ini adalah : beras ketan yang dijadikan jadah 7 warna; tebu wulung (tebu merah hati ) yang akan digunakan sebagai tangga; pasir yang akan digunakan injakan pasir; kurungan ayam; beras yang diberi pewarna kuning; koin; aneka macam bunga; barang-barang yang bermanfaat dan berharga seperti emas (gelang, kalung, cincin), uang, alat tulis, buku, al quran, mainan yang akan menjadi gambaran profesi yang akan dijalani sang anak kelak dimasa dewasa, alat kedokteran, alat musik, alat olah raga, dan sebagainya; sembako, sayur mayur yang akan dijadikan nasi tumpeng. Perlengkapan yang dapat digantikan adalah perlengkapan yang digunakan pada saat pemilihan barang yang dilakukan sang anak pada saat berada didalam kurungan ayam, perlengkapan dapat ditambahkan sesuai dengan kemajuan jaman.

Prosesi inti dilaksanakannya upacara tedhak siten meliputi berjalan melewati juadah/ jadah sebanyak tujuh buah; menaiki dan menuruni anak tangga tebu; menapaki pasir; memasuki kurungan ayam; memilih benda yang ada dalam kurungan ayam; menyebarkan udhik-udhik; mandi air kembang setaman; do'a dan pemotongan tumpeng. Alasan individu melakukan tedhak siten karena tradisi masyarakat sampai hari ini masih mempercayai dan melaksanakan tradisi tedhak siten di tanah jawa. Tedhak 
artinya menapakkan kaki dan siten berasal dari siti yang artinya bumi. Tradisi ini dilakukan oleh seorang bayi berumur 7-8 bulan (7 lapan) dan mulai belajar duduk dan berjalan di tanah. Dalam tradisi tedhak siten banyak informasi yang dapat dipelajari, salah satu alasan ini yang menjadikan sampai sekarang tradisi tedhak siten masih banyak dipercaya oleh masyarakat Jawa.

Menurut Bandura (1986) menyatakan bahwa self efficacy mengacu pada kepercayaan individu akan kemampuannya untuk sukses dalam melakukan sesuatu. Sedangkan self efficacy menurut Santrock (2007) adalah kepercayaan seseorang atas kemampuannya dalam menguasai situasi dan menghasilkan sesuatu yang menguntungkan. Sumbersumber self efficacy menurut Bandura dalam Lunenburg (2011), terdapat 4 sumber self efficacy antara lain past performance, vicarious experience, verbal persuasion dan emotional cues. Hal ini berkaitan dengan keempat sumber self efficacy terhadap tradisi tedhak siten yakni dijelaskan bahwa 7 proses pelaksanaan tradisi memiliki pengaruh terhadap self efficacy yang diyakini seseorang. Pengalaman yang lemah akan melemahkan keyakinannya pula. Individu yang memiliki keyakinan kuat terhadap kemampuan mereka akan teguh dalam berusaha untuk mengesampingkan kesulitan yang dihadapi dan tidak mudah kewalahan dalam menghadapi kesulitan. Dengan pengalaman tersebut akan timbul suatu kepercayaan diri yang ada dalam diri seseorang yang dapat ia wujudkan dalam meraih performa tertentu yakni keyakinan cita-cita pilihan karir seorang anak akan terwujud dikemudian hari.

Oleh karena itu, tujuan dari penulisan artikel ini adalah selain karena ketertarikan penulis ingin lebih memahami secara ilmiah kaitan antara kebudayaan tedhak siten dengan aspek psikologis, juga tertarik kaitannya antara karir dengan persepsi keluarga. Berdasarkan tujuan diatas, maka diharapkan penulisan artikel ini memberikan manfaat teoritis yaitu hasil penulisan ini menunjukkan bahwa proses upacara tedhak siten terkandung nilai kebaikan yang bersumber dari orang tua untuk anak mampu meraih cita-cita, yang berkaitan erat dengan teori psikologi yakni self efficacy.
Sedangkan manfaat praktis penelitian ini selain untuk menjawab pertanyaan penulis dan sebagai alternatif bahan studi sumber informasi tambahan bagi peneliti lain yang terkait tradisi tedhak siten, serta diharapkan agar masyarakat luas dapat mengenal dan mengerti tentang tedhak siten sebagai tradisi budaya Jawa yang masih dilestarikan dan dilaksankan di jaman modern ini. Berdasarkan hasil artikel maupun jurnal terdahulu menunjukkan bahwa proses upacara tedhak sinten terkandung nilai kebaikan yang bersumber dari orang tua untuk anak mampu meraih cita-cita, salah satu contohnya disaat seorang anak oleh orang tuanya disediakan dan mengambil kalkulator, disini orang tua memiliki keyakinan yang kuat bahwa nanti kedepannya anak tersebut akan menjadi ahli di bidang matematika. Hal ini berkaitan erat dengan teori psikologi yakni self efficacy.

\section{METODOLOGI}

Pada Metode penelitian menggunakan jenis penelitian studi kepustakaan. Studi kepustakaan memberikan penelusuran pustaka yang lebih dimana kegiatannya membatasi pada pengumpulan bahan-bahan koleksi perpustakaan (Zed, 2008). Langkahlangkah yang digunakan dala penelitian kepustakan meliputi (Khatibah, 2011):

1. Menyiapkan alat yang dibutuhkan dalam penelitian kepustakaan.

2. Menyusun bibliografi kerja atau sebuah catatan mengenai bahan sumber yang akan digunakan dalam penelitian kepustakaan.

3. Mengatur waktu dalam melakukan penelitian kepustakaan.

4. Membaca dan membuat sebuah catatancatatan penelitian.

\section{HASIL PEMBAHASAN}

Tedhak Sinten merupakan bagian dari adat dan tradisi masyarakat jawa, upacara ini dilakukan untuk anak yang baru pertama kali belajar berjalan atau menginjakkan pada tanah dan selalu ditunggu-tunggu oleh orang tua atau kerabat, tedak siten berasal dari dua kata "tedhak" berarti menampakkan kaki dan "siten" berasal dari kata "siti" yang berarti bumi, upacara ini dilakukan ketika seorang bayi berusia 7 bulan dan mulai belajar duduk dan berjalan di tanah, secara keseluruhan 
upacara ini bertujuan agar ia menjadi mandiri dimasa depan. Proses pelaksanaan upacara tedhak siten:

\section{Dititah}

Pada tahap ini, anak dibimbing berjalan (dititah) dengan kaki menginjak-injak juwadah (uli) yang berjumlah tujuh warna. Adapun pada tahap pertama ini, orang tua dari anak tersebut harus mengucapkan beberapa mantra, seperti: "Monggo, bapae gantosan kalian ibue nitah putrane melampah-melampah midak wajik, engkang werno-werno". Dilihat dari aspek psikologis, pada tahap ini berkaitan erat dengan dimensi past performance menurut Bandura dalam teori self efficacy yakni keyakinan diri meliputi hal-hal yang diterima sebagai hasil akumulasi kinerja/ pengalaman yang dimiliki sebelumnya. Disini pengalaman orang tua didapatkan dari hasil informasi leluhur turun temurun anggapan masyarakat bahwa tanah mempunyai kekuatan gaib dan disamping itu juga adanya suatu anggapan kuno bahwa tanah ada yang menjaga yaitu Batharakala. Maka dari itu si anak diperkenalkan kepada Batharakala sang penjaga tanah dengan ritual menginjak tanah agar Batharakala tidak marah dan mengganggu si anak. Dengan demikian disini orang tua muncul keyakinan kelak anaknya akan selalu ingat tanah airnya.

\section{Naik Tebu Wulung}

Kemudian anak tersebut dinaikkan ke tangga yang terbuat dari tebu wulung (merah hati). Adapun pada tahap kedua ini, orang tua dari anak tersebut harus mengucapkan beberapa mantra, seperti: "Sak sampunipun lajeng nitah putrane minggah dipun damel sakeng tebu". Dilihat dari aspek psikologis, tahap ini berkaitan erat dengan dimensi emotional cues menurut Bandura dalam teori self efficacy yakni keyakinan diri meliputi sikap emosi yang dirasakan orang tua pada saat anaknya menaiki tangga, apa yang dilakukan anaknya dalam menapaki (menjalani) hidupnya kelak. Disini terjadi peningkatan emosi dari orang tua yaitu indikator keyakinan agar anaknya dapat mencapai tujuan kehidupan yang sukses dan dinamis setahap demi setahap semakin meningkat sehingga mampu melewati halangan dan rintangan.

\section{Masuk ke kurungan ayam}

Selanjutnya pada tahap ini, anak dimasukkan ke dalam kurungan ayam bila anak tidak mau masuk maka perlu ditemani ibu atau pengasuhnya. Didalam kurungan telah dimasukkan berisi padi, gelang, cincin, alat-alat tulis, kapas, wayang kulit, mainan, uang, hp, stetoskop dan sebagainya. Kemudian orang tua dan keluarga menanti sampai anak tersebut mengambil benda yang dipilinnya. Adapun pada tahap ketiga ini, orang tua dari anak tersebut harus mengucapkan beberapa mantra, seperti: "Sak sampunipun dilajengngaken mlebet putrane dipun lebet taken woten kurungan pitek". Dilihat dari aspek psikologis, tahap ini berkaitan erat dengan dimensi vicarious experience menurut Bandura dalam teori self efficacy yakni keyakinan diri meliputi kesuksesan yang dirasakan sebagai pengalaman keberhasilan yang telah ditunjukkan orang lain maupun dirinya sendiri. Ketika orang tua melihat orang lain dengan kemampuan yang sama berhasil dalam suatu bidang, orang tua juga akan merasa yakin bahwa anaknya juga dapat berhasil dalam bidang tersebut. Hal ini sangat dipengaruhi oleh persepsi diri tentang kesamaan dengan model karir. Semakin anak mirip dengan model karir seseorang, maka kesuksesan akan tercapai. Disini ditunjukkan dengan meningkatnya keyakinan diri orang tua bahwa barang yang dipilih si anak merupakan gambaran dari kegemaran dan juga pekerjaan yang diminatinya kelak setelah dewasa.

\section{Pilih benda kesayangan}

Kemudian pada tahap keempat ini, orang tua dari anak tersebut harus mengucapkan beberapa mantra, seperti: "Sak niki maos dungo kagem putrane pun sepados putranipun dados tiang engkang sae kagem bongso ugi nagari ugi agami". Dilihat dari aspek psikologis, tahap ini berkaitan erat dengan dimensi past performance menurut Bandura dalam teori self efficacy yakni keyakinan diri meliputi hal-hal yang baru diterima sebagai hasil akumulasi kinerja/ pengalaman sebelumnya. Disini ditunjukkan peran orang tua menyediakan benda-benda dengan latar belakang benda kesayangan yakni memiliki riwayat yang berkaitan dengan kesuksesan jenis pekerjaan orang tua masa lalu maupun cita-cita orang tua yang belum 
sempat tercapai. Perumpamaan apabila anak mengambil alat-alat tulis, bagi orang tua ini adalah pertanda keyakinan bahwa anak akan menjadi pegawai kantor atau orang pandai, bila anak mengambil mainan pesawat keyakinan orang tua kelak anaknya akan menjadi pilot, bila anak itu mengambil salah satu benda misalnya gelang emas, orang tua meyakini pertanda kelak anaknya akan menjadi orang kaya.

\section{Rebut rerecehan}

Prosesi selanjutnya adalah sebar beras kuning yang telah dicampur dengan uang logam untuk diperebutkan tamu undangan yang hadir (dalam hal ini yang menaburkan adalah diwakili bapaknya). Dilihat dari aspek psikologis, tahap ini berkaitan erat dengan dimensi verbal cues menurut Bandura dalam teori self efficacy yakni keyakinan diri meliputi sikap/ gaya komunikasi yang diwakili bapaknya mengarahkan tamu undangan untuk memperebutkan beras kuning yang telah dicampur dengan uang logam. Disini muncul indikator keyakinan dari orang tua bahwa kelak anaknya mampu menjadi dermawan dan suka bersedekah dalam lingkungannya.

\section{Mandi air kembang}

Prosesi terakhir yaitu anak dimandikan dengan air bunga setaman. Dilihat dari aspek psikologis, tahap ini berkaitan erat dengan dimensi emotional cues menurut Bandura dalam teori self efficacy yakni keyakinan diri meliputi sikap emosi yang dirasakan orang tua. Disaat anak dimandikan air bunga setaman, terjadi peningkatan emosi/ meningkatnya efikasi diri orang tua yaitu muncul indikator keyakinan diri bahwa kelak anaknya akan membawa nama harum keluarga dan dapat menjalani kehidupan yang bersih dan lurus.

\section{Pakaian baru}

Setelah mandi anak dikenakan pakaian baru yang bagus. Dilihat dari aspek psikologis, tahap ini berkaitan erat dengan dimensi emotional cues menurut Bandura dalam teori self efficacy yakni keyakinan diri meliputi sikap emosi yang dirasakan orang tua. Disaat anak dikenakan pakaian baru yang bagus maka terjadi peningkatan emosi/ meningkatnya efikasi diri, sehingga muncul indikator keyakinan diri dari orang tua bahwa bau sedap anaknya akan menyenangkan orang tua serta para undangan yang hadir dalam prosesi ini. Setelah semua prosesi tersebut dilaksanakan, kemudian dilanjutkan memotong tumpeng yang dilengkapi dengan sayur urap (hidangan yang terbuat dari sayur kacang panjang, kangkung dan kecambah yang diberi bumbu kelapa yang telah dikukus, dan ayam).

Tradisi tedhak siten masih banyak dipercaya dan dilaksanakan oleh masyarakat Jawa hingga saat ini alasannya karena upacara ini dilakukan sebagai ucapan rasa syukur kepada Tuhan di saat seorang anak yang berumur 7-8 bulan mulai menapakkan kaki diatas bumi. Selain karena masyarakat beranggapan bahwa tanah mempunyai kekuatan gaib, juga masih adanya keyakinan yang memperkuat terhadap sumber-sumber self efficacy yang masyarakat yakini hingga saat ini.

\section{KESIMPULAN}

Sampai saat ini masyarakat masih mempercayai tradisi tedhak siten, persepsi awal yang dibangun ketika anak umur 7 bulan dengan pemilihan karir dan keluarga meyakini, ini merupakan semangat dalam perjalanan hidup sebagai patokan panduan untuk mewujudkannya dengan keyakinan diri (self efficacy) dari orang tua dan anak melalui usaha yang sungguh-sungguh. Berdasarkan hasil dari analisis data dan diskusi diatas, secara ilmiah ditemukan ada kaitan antara tradisi tedhak siten dengan aspek psikologis serta persepsi karir dalam keluarga. Penulis menyarankan tulisan ini digunakan sebagai bentuk kontribusi pada pengembangan sains khususnya ditinjau dari aspek psikologis.

Penulis mengharapkan kepada peneliti selanjutnya untuk menambah referensi sumber lain sehingga dapat memberikan manfaat pemahaman lebih kepada pembaca mengenai budaya tedhak sinten secara ilmiah berkaitan dengan aspek psikologis juga kaitannya dengan persepsi karir dalam keluarga.

\section{DAFTAR PUSTAKA}

Andi, W.P. (2014). Tradisi Thedak Siten Jawa dalam Pengembangan Karakter. Jurnal FIB USU, 31-37. 
Ardhani, P.K.D. (2016). Prosesi Upacara Tedhak Siten Anak Usia 7 bulan dalam tradisi Adat Jawa. Artikel Program Studi Pendidikan Pancasila dan Kewarganegaraan UNMUH Surakarta.

Devi, S.S.N. (2019). Upacara Tedhak Siten $\mathrm{Di}$ Desa Banyuanyar Kecamatan Banjarsari Kota Surakarta. Artikel Institut Seni Indonesia.

Ersanli, C.Y. (2015). The relationship between students academic self-efficacy and language learning motivation: A study of 8th graders. Journal Social and Behavioral Sciences, 199, 472-478.

Lavasani, M.G., Mirhosseini, F.S., Hejazi, E., \& Davoodi, M. (2011). The effect of selfregulation learning strategies training on the academic motivation and self-efficacy. Journal Social and Behavioral Sciences, 29, 627-632.

Nuryah. Tedhak Siten: Akulturasi Budaya Islam Jawa (Studi Kasus di Desa Kedawung, Kecamatan Pejagon, Kabupaten Kebumen). Jurnal Institut
Agama Islam Negeri Jurai Siwo Metro Lampung.

Panadero, E., Jonsson, A., \& Botella, J. (2017). Effects of self-regulated learning and self-efficacy: Four meta-analyses. Journal Educational Research Review, 22, 74-98.

Probowardhani, K.D. (2016). Prosesi Upacara Tedhak Siten Anak Usia 7 Bulan Dalam Tradisi Adat Jawa. Artikel UNMUH Surakarta.

Roshandel, J., Ghonsooly, B., \& Ghanizadeh, A. (2018). Motivational self-system and self-efficacy: A quantitative survey-based study. International Journal of Intruction, 11(1), 329-344.

Sugiati, R. (2019). Simbolisme Pada Tradisi Tedhak Siten (Ritual Turun Tanah) Di Desa Bandar Lor Kota Kediri. Artikel Universitas Nusantara PGRI Kediri. 